BeNTHAM OPEN
CrossMark
Content list available at: www.benthamopen.com/TORMJ/
DOI: $10.2174 / 1874306401610010029$

RESEARCH ARTICLE

\title{
Patterns of Drug Resistance Among Tuberculosis Patients in West and Northwestern Iran
}

Leyla Sahebi ${ }^{1}$, Khalil Ansarin ${ }^{1, *}$, Parviz Mohajeri ${ }^{2}$, Majid Khalili ${ }^{3}$, Amir Monfaredan ${ }^{4}$, Safar Farajnia $^{5}$ and Simin Khayyat Zadeh ${ }^{6}$

${ }^{\prime}$ Tuberculosis and Lung Disease Research Center, Tabriz University of Medical Science. Tabriz, Iran

${ }^{2}$ Microbiology Department, School of Medicine, Kermanshah University of Medical Sciences, Kermanshah, Iran

${ }^{3}$ Department of Basic Sciences, Maragheh Faculty of Medical Sciences, Maragheh, Iran

${ }^{4}$ Department of Hematology, Faculty of Medicine, Tabriz Branch, Islamic Azad University of Tabriz, Iran

${ }^{5}$ Drug Applied Research Center. Tabriz University of Medical Sciences, Tabriz, Iran

${ }^{6}$ Health Center of East Azerbaijan Province, Tabriz University of Medical Science, Tabriz, Iran

Received: October 06, 2015

Revised: January 15, 2016

Accepted: March 18, 2016

\section{Abstract:}

\section{Background:}

Tuberculosis (TB) is the leading cause of morbidity and mortality among chronic infectious diseases.

\section{Objective:}

The goal of this cross-sectional study (2011-2013;2013) was to examine the patterns of TB drug resistance among HIV-negative pulmonary TB patients in regions near the Iranian border.

\section{Method:}

To this end, MTB isolates were harvested from 300 HIV-negative, pulmonary smear-positive TB patients from the northwest and west Iranian border provinces. Isolates were subjected to first and second-line drug susceptibility testing by the $1 \%$ proportion method. Demographic and clinical data were provided using a questionnaire and information from patient records. Results were analyzed using SPSS-18.

Results:

The mean age of the patients was 52.03 years and $54.3 \%$ were male. The prevalence of resistance to any TB drug was $13.6 \%$ (38 cases). Eleven percent of the new treatment TB group (28 patients) and $40.7 \%$ of the retreatment TB group (11 patients) were resistant to all TB drugs. Twelve (4.3\%) patients had multidrug-resistant tuberculosis (MDR-TB) (2.38\% in the new TB treatment group and $23.1 \%$ in the retreatment group). One patient had extensively drug-resistant tuberculosis (XDR-TB). There was a statistically significant relationship between TB drug resistance and smoking $(\mathrm{p}=0.02)$ and a history of migration from village to city $(p=0.04)$, also between TB drug resistance and recurrence of TB in patients that had previously received treatment $(p<0.001)$.

\section{Conclusion:}

Knowledge of drug resistance patterns for new and previously treated cases is critical for effective control of MDR-TB in different regions of the country. The burden of MDR-TB in retreatment cases was high. Previous TB treatment was one of the most important mokers and those who had a history of rural to urban migration were at high risk for the occurrence of TB drug resistance.

\footnotetext{
* Address correspondence to this author at the Tuberculosis and Lung Disease Research Center, Tabriz University of Medical Sciences, Tabriz, Iran; Fax: 098-413-3378093; E-mail: dr.ansarin@gmail.com
} 
Keywords: Enzyme-linked immunosorbent assay, HIV-negative pulmonary TB patients, Löwenstein-Jensen, Multiple Drug Resistance, Mycobacterium Tuberculosis, Northwestern Iran, Tuberculosis (TB).

\section{INTRODUCTION}

Drug-resistant tuberculosis (MDR-TB) has emerged as an important global health concern and is on the rise throughout the world [1]. According to the 2012 World Health Organization (WHO) report, 3.7\% of new TB cases (patients who have never had treatment for TB, or had been on anti-TB treatment for less than four weeks) [2] and about $20 \%$ of retreatment patients (TB patients who had been cured for one month or more) [2] had MDR-TB in 2012. Nine percent of these patients in 2012 had extensive drug-resistant tuberculosis (XDR-TB) [3].

To be defined as MDR-TB, the patient shows resistance to at least isoniazid (INH) and rifampin (RMP) [3]. Furthermore, XDR-TB is defined as resistant to INH, RMP, any fluoroquinolone and any second-line injectable medications (i.e. amikacin, capreomycin and kanamycin) [4]. Treatment of MDR-TB is a costly and time-consuming (18 months) process which can be associated with numerous complications. The overall economic burden of an MDRTB patient is high and if left untreated, MDR-TB has an estimated $80 \%$ fatality rate [5].

It is notable that the highest rates of resistance in 2008 have been reported in Eastern Europe and East Mediterranean regions [6]. In Iran (2011), the proportion of MDR-TB cases of new and retreated TB cases were reported to be $5 \%$ and $38.3 \%$, respectively [5]. Due to the proximity to countries such as Azerbaijan, Armenia and Pakistan, which are among the 27 countries with the highest MDR-TB burden in world, the control of drug resistance is very pivotal in Iran [7].

The main strategy to control MDR-TB is the detection of drug resistance and to prescribe an effective drug course for patients [8]. Previous and inadequate treatment is of the main factors contributing to MDR-TB development [9].

The gold standard in MDR-TB determines is $1 \%$ proportion of Löwenstein-Jensen medium. Developed in the 1960s, the Löwenstein-Jensen medium is inexpensive and easy to perform [10]. In the present study, we evaluated the patterns of resistance to TB drugs based on the $1 \%$ proportion method among pulmonary TB patients from five provinces of patients in near the Iranian border; in addition, we analyzed the impact of geographic and demographic factors on TB drug resistance.

\section{METHODS}

\section{Sampling Method}

A cross-sectional survey was conducted on pulmonary TB patients in five Iranian west and northwestern provinces (East Azerbaijan, West Azerbaijan, Ardabil, Kurdistan and Kermanshah) that had been referred of rural and urban health centers to TB lab centers of province from April 2011 to March 2013. Proximity to the neighboring country of Azerbaijan and Iraq with high prevalence of TB and TB- drug resistance renders the need of study in this region. The University Ethics Committee code of study was 1391/6/18/5/4/5375.

Assuming a significance level $\mathrm{p}=0.05$, prevalence of MDR-TB $\mathrm{p}=0.05$ [4], margin of error $\mathrm{d}=0.018$, and considering the likelihood of missing cases, 300 positive smear tuberculosis patients with HIV negative test (ELISA test) were estimated based on proportional simple random sampling. The required sample size for each province was determined based on TB prevalence in the provinces in 2010; the sampling method in provinces was systematic on the basis of alphabetical order of patients' name.

\section{Laboratory Analysis}

Sputum- positive pulmonary TB was defined as TB in patients with at least two initial sputum smear examinations positive for acid-fast bacilli (AFB), one sputum smear test positive for AFB and radiographic abnormalities consistent with active pulmonary TB, or one sputum smear specimen positive for AFB and culture positive for Mycobacterium tuberculosis [9]. Two smears with the highest bacterial count were cultured on Lowenstein Jensen (LJ) culturing medium and one culture was selected for drug susceptibility test. The MTB complex strains were identified by culturing on LJ medium containing P-Nitro Benzoic acid (PNB). But differentiation of MTB from other members of the MTB complex was identified based on niacin test and Nitratase test. The samples containing non-tuberculosis mycobacterium were excluded from this study. Drug susceptibility was tested on LJ medium containing Isoniazid (INH); $0.2 \mathrm{mg} / \mathrm{l}$, Rifampicine (RMP);40mg/l, Ethambutol (EMB);2mg/l, Streptomycin (SM);4mg/l and second line drugs including 
Kanamycin; $30 \mathrm{mg} / \mathrm{l}$, Capreomycin;40 mg/l, Ofloxacin;20 mg/l and Ciprofloxacin; $2 \mathrm{mg} / \mathrm{l}$ according to the proportion method based on WHO/IUTLD guideline $[11,12]$.

\section{Demographic Variable}

The data related to clinical, demographic and environmental characteristics were provided using the information mentioned in the patient's records as well as personal or telephone interviews. It should be said that the data of the patients under 15 years was completed by the help of the patient's parents and the information of the deceased patients was filled in by the closest person to the patient. In a pilot study, the validity of the questionnaire was evaluated as confirmed by expert professors and its reliability was assessed using statistical reliability test (Cronbach's alphas $=0.92$.

\section{Statistical Analysis}

Univariate and multiple logistic regressions were used to compare the effect of demographic and geographical factors on drug resistance considering significance level of 0.05 using SPSS-18 software (IBM, Armonk, New York, USA).

\section{RESULTS}

Out of 300 patients with MTB, 286 had a positive culture. In the drug resistance analysis sample, six cultures were contaminated and therefore 280 cases were available for drug resistance analysis.

To populate our study, 96 patients (34.29\%) from East Azerbaijan, 53 (18.93\%) from Kermanshah, 45 (16.08\%) from West Azerbaijan, 56 (20.0\%) from Kurdistan and 30 (10.72\%) from Ardabil provinces were selected. All of the patients were HIV negative.

The overall frequency of new and retreatment TB groups was $253(90.36 \%)$ and 27 (9.64\%) patients, respectively. The mean age of patients available for drug resistance analysis was 52.03 years and 152 patients $(54.3 \%)$ were male. Resistance to RMP was found in $11.8 \%$ of cases (33 patients) and following by Streptomycin (STM) with $10.7 \%$ (30 patients) had the highest proportions among anti-tuberculosis drugs while resistance to ethambutol (EMB) in $3.2 \%(9$ patients) showed the least rate of resistance (see Table 1). Eleven percent of new TB cases (28 patients) and $40.7 \%$ of retreatment TB cases (11 patients) were resistant to any TB drug.

Table 1. Drug resistance pattern among pulmonary MTB patients.

\begin{tabular}{|c|c|c|c|c|c|c|}
\hline & $\begin{array}{c}\text { Total (280) } \\
\mathbf{n ~ ( \% )}\end{array}$ & $\begin{array}{c}\text { East Azerbaijan } \\
\mathbf{( 9 6 )} \\
\mathbf{n}(\mathbf{\%})\end{array}$ & $\begin{array}{c}\text { West Azerbaijan } \\
\mathbf{( 4 5 )} \\
\mathbf{n}(\mathbf{\%})\end{array}$ & $\begin{array}{c}\text { Ardebil (30) } \\
\mathbf{n}(\mathbf{\%})\end{array}$ & $\begin{array}{c}\text { Kermanshah(53) } \\
\mathbf{n}(\mathbf{\%})\end{array}$ & $\begin{array}{c}\text { Kurdistan (56) } \\
\mathbf{n}(\mathbf{\%})\end{array}$ \\
\hline Any resistance to Isoniazid (INH) & $28(10.0)$ & $8(8.33)$ & $4(8.9)$ & $4(13.33)$ & $5(9.43)$ & $7(12.5)$ \\
\hline Any resistance to Rifampicin (RMP) & $33(11.8)$ & $6(6.25)$ & $7(17.5)$ & $4(13.33)$ & $9(16.98)$ & $7(14.0)$ \\
\hline Any resistance to Etambutol (EMB) & $9(3.2)$ & $2(2.08)$ & $0(0.0)$ & $2(6.7)$ & $2(3.77)$ & $3(5.3)$ \\
\hline Any resistance to Streptomycin (STM) & $30(10.7)$ & $9(9.37)$ & $5(12.5)$ & $3(10.0)$ & $7(13.2)$ & $6(10.71)$ \\
\hline Total Multidrug Resistance (MDR) & $12(4.3)$ & $3(3.12)$ & $2(4.44)$ & $2(6.67)$ & $3(5.66)$ & $2(3.57)$ \\
\hline Total poly- resistance other than MDR & $4(1.43)$ & $1(1.04)$ & $0(0.0)$ & $1(3.33)$ & $1(1.9)$ & $1(1.79)$ \\
\hline $\begin{array}{c}\text { Any drug resistant to both of FQ* and any 2- } \\
\text { LI* in MDR-TB patients }\end{array}$ & $1(0.36)$ & $1(1.04)$ & $0(0.0)$ & $0(0.0)$ & $0(0.0)$ & $0(0.0)$ \\
\hline
\end{tabular}

*Fluroquinolones: Ofloxacin, Levofloxacin

* Injectable agent: Streptomycin, Kanamycin, Amikacin, Capreomycin

In the retreatment TB group, resistance to INH was found in $23.1 \%$ (6 cases), RMP: $15.4 \%$ (4 cases), STM: $15.4 \%$ (4 cases) and EMB: 0\%. MDR-TB and XDR-TB prevalence was $23.1 \%$ (6 cases) and 3.8\% ( 1 case), respectively. In regards to the new TB group, any resistance to INH was 6.7\% (17 cases), RMP: 4.33\% (11 cases), EMB: $2.77 \%$ (7 cases) and STM: 7.9\% (20 cases). MDR-TB and XDR-TB prevalence was $2.38 \%$ (6 cases) and $0 \%$, and total polyresistance other than MDR was $1.17 \%$ (3 cases).

The prevalence of drug resistance by various provinces is shown in Table 1. Resistance to INH was found to be the most prevalent in the province of Ardebil (13.33\%), RMP (14\%) and EMB (5.3\%) in Kurdistan, and STM (13.2\%) in Kermanshah. Also MDR-TB prevalence was the most common in Ardebil (6.67\%). There wasn't any relationship between different provinces and any TB drug resistance $(\mathrm{p}>.05)$

We analyzed the effect of demographic and geographical factors on resistance to TB drugs by univariate and 
multiple logistic regression tests (See Table 2). In the multiple models, variables with a p-value of $\leq 0.1$ were included and reanalyzed. The odds of resistance to one or more TB drugs was significantly high in retreatment cases compared to newly diagnosed cases in univariate (CI 95\% 2.42 to 13.67) and multiple regression analyses (CI 95\%:1.43 to 25.0). Migration history from village to city and smoking increased odds of drug resistance as well (CI 95\% OR: 1.05 to 4.2) and (CI 95\% OR: 1.36 to 5.5) in univariate regression analysis (See Table 2).

Table 2. Analyzing of demographic and clinical characteristics on TB drugs resistance among pulmonary MTB patient.

\begin{tabular}{|c|c|c|c|c|c|c|c|c|c|}
\hline \multirow[t]{2}{*}{ Variable } & & \multirow{2}{*}{$\begin{array}{l}\text { Any drug } \\
\text { resistance } \\
\quad(n=38)\end{array}$} & \multirow{2}{*}{$\begin{array}{c}\text { Drug susceptible } \\
(\mathrm{n}=\mathbf{2 4 2})\end{array}$} & \multicolumn{3}{|c|}{ Univariate analysis } & \multicolumn{3}{|c|}{ Multiple analysis } \\
\hline & & & & $\begin{array}{c}\text { Unadjusted } \\
\text { OR }\end{array}$ & CI95\%(OR) & P-Value & $\begin{array}{l}\text { Adjusted } \\
\text { OR }\end{array}$ & CI95\%(OR) & P-Value \\
\hline \multirow[t]{2}{*}{ Gender } & Male & $26(68.4)$ & $126(52.0)$ & 1 & - & - & 1 & - & - \\
\hline & Female & $12(31.6)$ & $116(48.0)$ & 2.0 & 0.96 to 4.13 & 0.06 & 0.9 & 0.06 to 13.1 & 0.95 \\
\hline Age & Mean (Year) & $52.29(22.8)$ & $49.24(21.2)$ & .99 & $0.97-1.02$ & 0.64 & 1.02 & 0.93 to 1.08 & 0.71 \\
\hline \multirow[t]{5}{*}{ Provinces } & East Azerbaijan & $12(31.58)$ & $84(68.42)$ & 1 & - & - & - & - & - \\
\hline & West Azerbaijan & $7(18.42)$ & $40(81.58)$ & 1.2 & 0.45 to 3.35 & 0.69 & - & - & - \\
\hline & Ardebil & $5(13.16)$ & $25(86.84)$ & 1.4 & 0.45 to 4.35 & 0.56 & - & - & - \\
\hline & Kurdistan & $7(18.42)$ & $48(81.58)$ & 1.02 & 0.37 to 2.77 & 2.77 & - & - & - \\
\hline & Kermanshah & $7(18.42)$ & $49(81.58)$ & 1 & 0.36 to 2.7 & 1 & & & \\
\hline \multirow[t]{3}{*}{ Married status } & Single & $6(15.7)$ & $51(21.0)$ & 1 & - & - & - & - & - \\
\hline & Married & $27(71.1)$ & $148(61.2)$ & 0.65 & 0.25 to 1.65 & 0.36 & - & - & - \\
\hline & $\begin{array}{c}\text { Divorced/Died } \\
\text { spouse }\end{array}$ & $5(13.2)$ & $43(17.8)$ & 1.0 & 0.29 to 3.55 & 0.98 & & & \\
\hline \multirow{3}{*}{$\begin{array}{c}\text { Income (on } \\
\text { married } \\
\text { patients) }\end{array}$} & Zero & $9(25.0)$ & $65(28.4)$ & 1 & - & - & - & - & - \\
\hline & $<100 \$$ & $18(50.0)$ & $93(40.6)$ & 0.72 & 0.3 to 1.69 & 0.44 & - & - & - \\
\hline & $\geq 100 \$$ & $9(25.0)$ & $71(31.0)$ & 1.0923 & 0.41 to 2.9 & 0.86 & - & - & - \\
\hline SES* & $\operatorname{Mean}(\mathrm{SD})$ & $6.9(3.01)$ & $6.47(3.7)$ & 1.04 & .89 to 1.2 & 0.67 & 0.96 & 0.7 to 1.29 & 0.78 \\
\hline \multirow{2}{*}{$\begin{array}{l}\text { History of } \\
\text { Migration }\end{array}$} & No & $18(47.4)$ & $170(70.0)$ & 1 & - & - & - & - & - \\
\hline & Yes & $20(52.7)$ & $73(30.0)$ & 2.09 & 1.05 to 4.2 & 0.037 & 0.96 & 0.28 to 3.3 & 0.95 \\
\hline \multirow[t]{2}{*}{ Smoking } & No & $19(0.5)$ & $177(72.8)$ & 1 & & & 1 & - & - \\
\hline & Yes & $19(0.5)$ & $65(27.2)$ & 2.7 & 1.36 to 5.46 & 0.005 & 1.16 & .08 to 16.68 & 0.92 \\
\hline \multirow{2}{*}{$\begin{array}{l}\text { Vaccination } \\
\text { history }\end{array}$} & No & $20(68.9)$ & 131(71.97) & 1 & - & - & 1 & - & - \\
\hline & Yes & $9(31.1)$ & $51(28.13)$ & 1.2 & 0.49 to 2.7 & 0.739 & 2.48 & 0.85 to 1.23 & 0.81 \\
\hline \multirow{2}{*}{$\begin{array}{l}\text { Treatment } \\
\text { group* }\end{array}$} & New & $27(71.1)$ & $226(93.4)$ & 1 & - & - & 1 & - & - \\
\hline & Other & $11(28.9)$ & $16(6.6)$ & 5.75 & 2.42 to 13.67 & 0.0001 & 5.76 & 1.43 to 25 & 0.025 \\
\hline
\end{tabular}

*SES; Social-Economic status combining of patient Job (Regardless housekeeper job) and education status, spouse Job (Regardless house keeper job) and education status and family income among married patients.(Grading: Job; 1:Unemployment, 2: Unskilled worker,3:Semi and skilled worker,4: Staff education . Education status; 1: Illiterate, 2: Reading, 3: Middle school, 4: Diploma, 5: Upper diploma. Family income; 1: <117 USD, 2:117-156 USD, 3: 157-313 USD, 4:> 313 USD.

*Treatment group; New: never been treated for TB or have taken anti-TB drugs for less than 1 month previously treated (retreatment): have received 1 month or more of anti-TB drugs in the past.

\section{DISCUSSION}

The emergence of TB drug resistance is a great catastrophe because it requires the use of second-line drugs which are less efficient, have longer treatment periods, higher expenses and patients run the risk of developing hepatotoxicity $[13,14]$.On the other hand, MDR-TB has increased throughout the world over the past few decades [4]. According to the global project on anti-TB drug resistance surveillance in 2009 , the median prevalence of resistance to any drug was $11.1 \%$ and $25.1 \%$ in new and previously treated cases, respectively [15].

However, it seems that Iran has a moderate drug resistance rate in new cases compared to global estimates, but proximity to the Azerbaijan Republic (with a prevalence of $56.3 \%$ and $84.4 \%$ drug resistance in new and retreated cases, respectively) [15] necessitates the task of controlling drug resistance

Also MDR-TB in new and previously treated cases $(2.38 \%$ and $23.1 \%$ for new and previously treated cases, respectively in our study) was reported as lower than the rates reported for the WHO Eastern Mediterranean region [16].

The average of MDR-TB prevalence in Iran (studies of 1997 to 2010) was 18.3\% [13, 14, 17 - 21]. The discrepancy of drug resistance with other Iranian studies can be explained by the diversities in the source population. In the available studies from Iran, the studies consisted of Iranian and Afghan patients [13, 20, 21]. As reported by the WHO global 
project over 1999-2002, Afghan patients comprised a high percentage of MDR-TB cases in Iran [22]. In our study, however, we solely screened and sampled Iranians.

We found that a case of XDR among MDR-TB patients that should be a warning sign. XDR-TB is documented in 2006 by Masjedi, et al. in Iran (10.9\% of MTB strains) [21]. Globally, $10 \%$ of all MDR-TB cases are XDR, (ranging from $4 \%$ in Armenia to $23.7 \%$ in Estonia) [15]. In our study, the prevalence of drug resistance was the highest for RMP following by STM. This result is almost consistent with other Iranian studies [13, 14, 17 - 21].

Different studies in the analysis of various factors on TB drug resistance such as immigration, age, sex and smoking on drug resistance have yielded conflicting results [13, 17, 20, 23 - 26], but MDR risk factors have not been fully investigated in Iran [23]. In consistency with our study, immigration and smoking have been suggested as a leading factor in increasing prevalence of MDR-TB in some countries [25 - 27]. History of TB previous treatment was one of the most important risk factors for development of drug-resistant TB in consistency with some studies $[18,20,24,28$, 29].

\section{CONCLUSION}

As a result, in our study, the proportion of TB drug resistance in new cases was similar to global estimates, while drug resistance in retreated cases was about 1.6 times the global rate. In this study, smokers and those who had a history from village to city were high-risk groups in the occurrence of TB drug resistance. Knowledge of drug resistance patterns for new and previously treated cases is critical for the effective control of MDR-TB.

\section{LIST OF ABBREVIATIONS}

$\begin{array}{lll}\text { ELISA } & = & \text { Enzyme-linked Immunosorbent Assay } \\ \text { EMB } & = & \text { Ethambutol } \\ \text { INH } & = & \text { Isoniazid } \\ \text { MDR } & = & \text { Multidrug-resistant } \\ \text { MTB } & = & \text { Mycobacterium Tuberculosis } \\ \text { RMP } & = & \text { Rifampin } \\ \text { SPSS } & = & \text { Statistical Package for the Social Sciences } \\ \text { STM } & = & \text { Streptomycin } \\ \text { TB } & = & \text { Tuberculosis } \\ \text { WHO } & = & \text { World Health Organization } \\ \text { XDR } & = & \text { Extensively Drug-resistant Tuberculosis }\end{array}$

\section{CONFLICT OF INTEREST}

The authors confirm that this article content has no conflict of interest.

\section{ACKNOWLEDGEMENTS}

The authors thank the staff of East Azerbaijan reference laboratory, TB \& Lung Disease Research Center and Province Health Center, Tabriz University of Medical Sciences and Mrs Seyyedi, MSC of Biotechnology; Ahad Zarei; BSC of Lab Sciences, Hasan Yekrang; Ms.c of Health Service Management, Dr. Hamed Sabbagh jadid, MD, Staff of West Azerbaijan laboratory and province health center: Dr. Tavana; MD, Dr Nemati; MD, Mr Seyyedi and Sarhangi, BSC of Lab Sciences. Staff of Ardabil laboratory and province health center: Dr. Arezu Moini; MD and Mrs. Saraii; BSC of Lab Sciences. Staff of Kermanshah reference laboratory: Sara Atashi; BSC of lab sciences, Kamalledin Jadidian; M.Sc. of microbiology. Staff of Kurdistan laboratory and province health center: Mrs. Seyran nili; Epidemiologist, Mr Galilini; BSC of lab sciences . and many thanks of Mrs. Lesley Carson for Editorial Solutions.This research was part of a PhD thesis and supported by Tabriz Tuberculosis and Lung Disease Research Center. Tabriz University of Medical Sciences.

\section{REFERENCES}

[1] Sharma SK, Kumar S, Saha PK, et al. Prevalence of multidrug-resistant tuberculosis among category II pulmonary tuberculosis patients. Indian J Med Res 2011; 133: 312-5.

[PMID: 21441686] 
[2] World Health Organization. Multidrug-resistant tuberculosis (MDR-TB). WHO Reference. Available from: http://www.WHO.int/TB/publications/ MDRFactSheet2012.pdf [2012].

[3] World Health Organization. Tuberculosis MDR-TB\&XDR-TB. WHO report Reference. Available from: http://www.WHO.int/TB/challenges/ MDR/factsheet_MDR_progress_march 2011.pdf [2011].

[4] Khoharo HK, Shaikh IA. Drug resistance patterns in pulmonary tuberculosis. J Pak Med Assoc 2011; 61(3): $229-32$. [PMID: 21465933]

[5] World Health Organization. EMRO, stop tuberculosis, Epidemiological situation. Reference Available from: http://www.emro.who.int/ tuberculosis/epidemiological-situation/epidemiological-situation.html

[6] He GX, Zhao YL, Jiang GL, et al. Prevalence of tuberculosis drug resistance in 10 provinces of China. BMC Infect Dis 2008 ; 8: 166. [http://dx.doi.org/10.1186/1471-2334-8-166] [PMID: 19077223]

[7] Sahebi L, Ansarin K, Farajnia S, Monfaredan A, Sabour S. Prevalence and risk factors of drug-resistant tuberculosis in border provinces of Iran. Postgrad Med 2015; 127(6): 600-6 [http://dx.doi.org/10.1080/00325481.2015.1069168] [PMID: 26174471]

[8] Farmer P. The major infectious diseases in the world-to treat or not to treat? N Engl J Med 2001; 345(3): 208-10. [http://dx.doi.org/10.1056/NEJM200107193450310] [PMID: 11463018]

[9] Yew WW, Leung CC. Management of multidrug-resistant tuberculosis: Update 2007. Respirology 2008; 13(1): 21-46. [PMID: 18197909]

[10] Sharma SK, Kaushik G, Jha B, et al. Prevalence of multidrug-resistant tuberculosis among newly diagnosed cases of sputum-positive pulmonary tuberculosis. Indian J Med Res 2011; 133: 308-11. [PMID: 21441685]

[11] World Health Organization. Anti-tuberculosis drug resistance in the world In: In Report no 4 WHO/HTM/TB/2008394. Geneva, Switzerland: WHO 2008

[12] Guidelines for surveillance of drug resistance in tuberculosis. In: WHO/TB/96216Geneva. Switzerland: WHO 1997.

[13] Merza MA, Farnia P, Tabarsi P, Khazampour M, Masjedi MR, Velayati AA. Anti-tuberculosis drug resistance and associated risk factors in a tertiary level TB center in Iran: a retrospective analysis. J Infect Dev Ctries 2011; 5(7): 511-9. [http://dx.doi.org/10.3855/jidc.1259] [PMID: 21795819]

[14] Velayati AA, Farnia P, Masjedi MR, et al. Totally drug-resistant tuberculosis strains: evidence of adaptation at the cellular level. Eur Respir J 2009; 34(5): 1202-3. [http://dx.doi.org/10.1183/09031936.00081909] [PMID: 19880622]

[15] Wright A, Zignol M, Van Deun A, et al. Global project on anti-tuberculosis drug resistance surveillance. Epidemiology of antituberculosis drug resistance 2002-07: an updated analysis of the Global Project on Anti-Tuberculosis Drug Resistance Surveillance. Lancet 2009; 373(9678): 1861-73.

[http://dx.doi.org/10.1016/S0140-6736(09)60331-7] [PMID: 19375159]

[16] Weis SE, Slocum PC, Blais FX, et al. The effect of directly observed therapy on the rates of drug resistance and relapse in tuberculosis. N Engl J Med 1994; 330(17): 1179-84 [http://dx.doi.org/10.1056/NEJM199404283301702] [PMID: 8139628]

[17] Bahrmand AR, Velayati AA, Bakayev VV. Treatment monitoring and prevalence of drug resistance in tuberculosis patients in Tehran. Int J Tuberc Lung Dis 2000; 4(6): 544-9. [PMID: 10864185]

[18] Shamaei M, Marjani M, Chitsaz E, et al. First-line anti-tuberculosis drug resistance patterns and trends at the national TB referral center in Iran-eight years of surveillance. Int J Infect Dis 2009; 13: 236-40. [http://dx.doi.org/10.1016/j.ijid.2008.11.027] [PMID: 18838283]

[19] Mirsaeidi MS, Tabarsi P, Farnia P, et al. Trends of drug resistant Mycobacterium tuberculosis in a tertiary tuberculosis center in Iran. Saudi Med J 2007; 28(4): 544-50. [PMID: 17457475]

[20] Mansoori SD, Arami S, Mirabolhasani Z, Farnia P, Velayati AA. The Pattern of drug resistance among newly diagnosed and old cases of pulmonary tuberculosis. Arch Iran Med 2003; 6: 255-60.

[21] Masjedi MR, Farnia P, Sorooch S, et al. Extensively drug-resistant tuberculosis: 2 years of surveillance in Iran. Clin Infect Dis 2006; 43(7): 841-7. [http://dx.doi.org/10.1086/507542] [PMID: 16941364]

[22] Ramazanzadeh R, Farnia P, Amirmozafari N, et al. Comparison between molecular epidemiology, geographical regions and drug resistance in Mycobacterium tuberculosis strains isolated from Iranian and Afghan patients. Chemotherapy 2006; 52(6): 316-20. [http://dx.doi.org/10.1159/000095971] [PMID: 17008783]

[23] Massi MN, Wahyuni S, Halik H, et al. Drug resistance among tuberculosis patients attending diagnostic and treatment centres in Makassar, Indonesia. Int J Tuberc Lung Dis 2011; 15(4): 489-95. [http://dx.doi.org/10.5588/ijtld.09.0730] [PMID: 21396208] 
[24] Mdivani N, Zangaladze E, Volkova N, et al. High prevalence of multidrug-resistant tuberculosis in Georgia. Int J Infect Dis 2008; 12(6): 635-44.

[http://dx.doi.org/10.1016/j.ijid.2008.03.012] [PMID: 18514008]

[25] Trakada G, Tsiamita M, Spiropoulos K. Drug-resistance of Mycobacterium tuberculosis in Patras, Greece. Monaldi Arch Chest Dis 2004; 61(1): 65-70. [PMID: 15366340]

[26] World Health Organization. Multidrug and extensively drug-resistant TB (M/XDR-TB) 2010 Global Report on Surveillance and Response WHO/HTM/TB/20103. Geneva,Switzerland: WHO 2010.

[27] Marahatta SB, Kaewkungwal J, Ramasoota P, Singhasivanon P. Risk factors of multidrug resistant tuberculosis in central Nepal: a pilot study. Kathmandu Univ Med J (KUMJ) 2010; 8(32): 392-7. [PMID: 22610768]

[28] Baghaei P, Tabarsi P, Chitsaz E, et al. Risk factors associated with multidrug-resistant tuberculosis. Tanaffos 2009; 8: 17-21.

[29] Espinal MA, Laszlo A, Simonsen L, et al. Global trends in resistance to antituberculosis drugs. World Health Organization-International Union against Tuberculosis and Lung Disease Working Group on Anti-Tuberculosis Drug Resistance Surveillance. N Engl J Med 2001; 344(17): 1294-303.

[http://dx.doi.org/10.1056/NEJM200104263441706] [PMID: 11320389]

(C) Sahebi et al.; Licensee Bentham Open.

This is an open access article licensed under the terms of the Creative Commons Attribution-Non-Commercial 4.0 International Public License (CC BY-NC 4.0) (https://creativecommons.org/licenses/by-nc/4.0/legalcode), which permits unrestricted, non-commercial use, distribution and reproduction in any medium, provided the work is properly cited. 